\title{
Performance Improvement of U-Slot Microstrip Patch Antenna for RF Portable Devices using Electromagnetic Band Gap and Defected Ground Structure
}

\author{
Nitika Mittal, Rajesh Khanna and Jaswinder Kaur \\ Department of Electronics and Communication Engineering Thapar University, Patiala, 147004, Punjab, India
}

\begin{abstract}
This paper presents a microstrip patch antenna incorporated with electromagnetic band gap (EBG) structure on substrate and defected ground structure (DGS) in the ground plane. Electromagnetic Band Gap materials are artificially engineered structures that improve the performance of the patch antennas. It is manifested that applications of both EBG and DGS outcomes in the remarkable improvement of return loss level from -20.2dB to $-31.5 \mathrm{~dB}$ and bandwidth from $155 \mathrm{MHz}$ to $202 \mathrm{MHz}$ respectively. The most fascinating characteristic of the proposal is the capability of increasing the gain, directivity and the total efficiency of the antenna without affecting the other essential parameter like bandwidth which makes the designed antenna applicable for Radio Frequency portable devices operating at $6.1 \mathrm{GHz}$.
\end{abstract}

Index Terms: Microstrip patch antenna, Electromagnetic Band Gap (EBG), RF Portable Devices, Defected Ground Structure (DGS).

(C) 2016 Published by MECS Publisher. Selection and/or peer review under responsibility of the Research Association of Modern Education and Computer Science

\section{Introduction}

In recent years, there has been magnifying interest in exploring the microstrip patch antenna along with various periodic compositions including EBG [1] and DGS [2] for various applications like wide stop band in transmission characteristics [3], low-pass and band-pass filter designs [4], harmonic suppression [5]. Generally, the defects are generated by etching a single or periodic pattern on the ground plane for the formation of DGS. Actually, distinct geometrical shapes have been analyzed so far and they include circles, rectangles, dumbbells [6], spirals [7], H-shape [5], L-shape [8-9], O-shape [10] and fractal configurations [11].

In this article, we describe a new technology developed in the modern antenna design called mushroom type electromagnetic band gap structure and DGS approach collectively for composing low profile antenna such as

* Corresponding author

E-mail address: 
microstrip antenna. The DGS regarded as a simplified form of Electromagnetic Band Gap (EBG) structure is evolved from it. Its application includes microstrip transmission lines and circuits and manifests a band-stop property. Different shapes of slots in the ground plane have been explored in the past such as V, S, L, and $\mathrm{H}$ etc. [12]. The introduction of slots disturbs the path of the current in the patch and thus brings about dual band properties in the patch antenna. Microstrip patch antennas possess certain type of waves along the radiated waves that greatly reduce the performance of the antenna. These waves which enormously impact on the performance of patch antennas are called surface waves. The guided waves that are apprehended within the substrate and partly radiated and reflected back at the substrate edges are called surface waves. Electromagnetic Band Gap materials reduce these surface waves acting like stop band filter for them, hence the surface waves are mitigated and as a result the performance of the antenna is improved. As a result return loss is increased. The bandwidth of the designed antenna can be increased by symmetrical circular shaped DGS on the ground plane [13]. The designed antenna has been studied intensely and the results have been simulated using 3D Electromagnetic simulator-Computer Simulation Technology Microwave Studio Version 10.0 (CST-MWS V10.0).

\section{Antenna Design and Specifications}

Fig. 1(a) depicts the front view of the U-slot microstrip patch antenna on one side of a dielectric substrate including the mushroom type EBG structure surrounding the patch, Fig. 1(b) illustrates the back view of MPA demonstrating the modified ground structure using circular and Fig. 1(c) shows the structure of electromagnetic band gap. Initially, taking only the U-Slot in the patch without incorporating EBG and DGS, the antenna resonates at $6.1 \mathrm{GHz}$ occupying a bandwidth of $155 \mathrm{MHz}$. The antenna was fed using microstrip feed line having the characteristic impedance of $50 \Omega$ in order to match the input impedance of the patch antenna. The substrate used for the antenna is FR4 having dimensions $\mathrm{L}_{\text {sub }} \times \mathrm{W}_{\text {sub }} \times \mathrm{H}_{\text {sub }}=53 \times 43 \times 1.6 \mathrm{~mm}^{3}$ and relative permittivity, $\varepsilon_{\mathrm{r}=} 4.3$ and loss tangent, $\tan \delta=0.0024$. A ground plane is used below the substrate having equal length. The patch situated on the substrate and the ground plane is Perfect Electric Conductors (PECs) made of conducting material usually copper. The ground plane acts as a body that reflects electromagnetic waves thus creating a directional radiation pattern. A U-slot with dimensions $\mathrm{Bs}=2.4, \mathrm{Ls}=12 \mathrm{~mm}, \mathrm{Ws}=10.5 \mathrm{~mm}$ is made in the patch with dimensions $\mathrm{Lp}=21.5 \mathrm{~mm}$ and $\mathrm{Wp}=26.5 \mathrm{~mm}$.

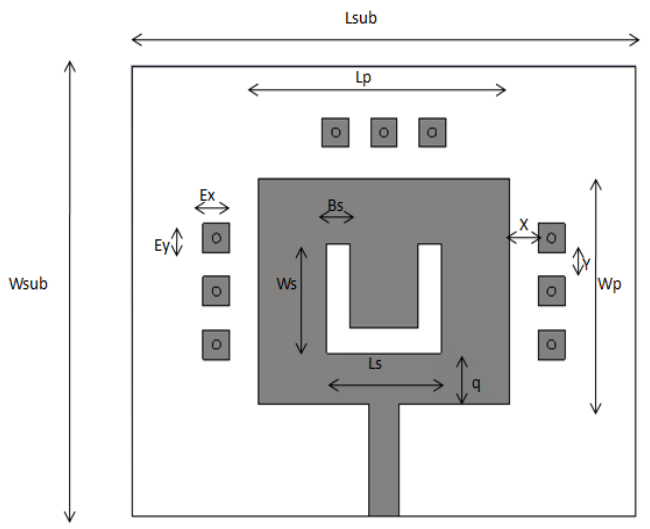

(a) 


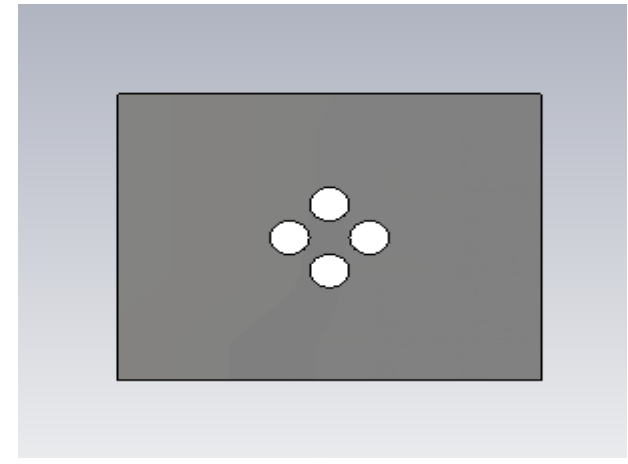

(b)

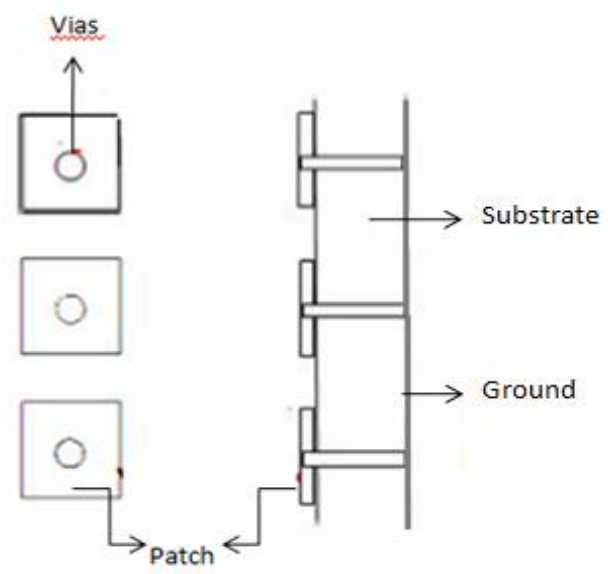

(c)

Fig.1. Geometrical Configuration of the Proposed Antenna: (a) Front view - Radiating structure having U-slot surrounded by EBG structure, (b) Back view - Defected Ground Structure, (c) EBG Structure

In order to enhance the bandwidth of proposed U-slot MPA, defected ground structure with the shape of circular patches is used [14]. Bandwidth has been increased to $202 \mathrm{MHz}$ using this approach. But the return loss was still not satisfactory. So, further the technique used to improve the return loss was artificially introduced mushroom-like EBG structure connected with ground plane through a vias. This approach prevented the electromagnetic waves from being reflected within the substrate and hence leading to constructive addition with the space waves, thus resulting in the decrease of back lobe radiations and suppression of surface waves. These EBG structures were introduced on the substrate while keeping other parameters of the antenna unaffected. The position, size, gap between EBGs and number of EBG structures were changed and improvement was evident after doing a number of trials. The return loss initially was $-20.2 \mathrm{~dB}$ and was improved remarkably to $-31.5 \mathrm{~dB}$ using EBG structures [15].

The optimal parameters of the aforementioned antenna are bestowed in Table 1 . 
Table 1. Optimized Specifications of the Proposed Antenna

\begin{tabular}{|l|l|}
\hline Parameters & Value(mm) \\
\hline Lsub & 53 \\
\hline Wsub & 43 \\
\hline Lp & 26.5 \\
\hline Wp & 21.5 \\
\hline Ls & 12 \\
\hline Ws & 10.5 \\
\hline Bs & 2.4 \\
\hline Q & 4.81 \\
\hline X & 3.01 \\
\hline Y & 2.29 \\
\hline EBG Patch(Ex) & 2.80 \\
\hline EBG Patch(Ex) & 2.80 \\
\hline EBG Vias & 0.44 \\
\hline DGS circular slot radius & 2.5 \\
\hline
\end{tabular}

\section{Results and Discussion}

The dimensions of proposed antenna are optimized by hit and trial method using parameter sweep option available in transient solver window of CST MICROWAVE STUDIO Version 10.0.

\subsection{Return Loss}

$\mathrm{S}_{11}$ parameter indicates return loss and it is defined as maximum reflection of power from the given antenna.The various simulated results are illustrated in Fig. 2.

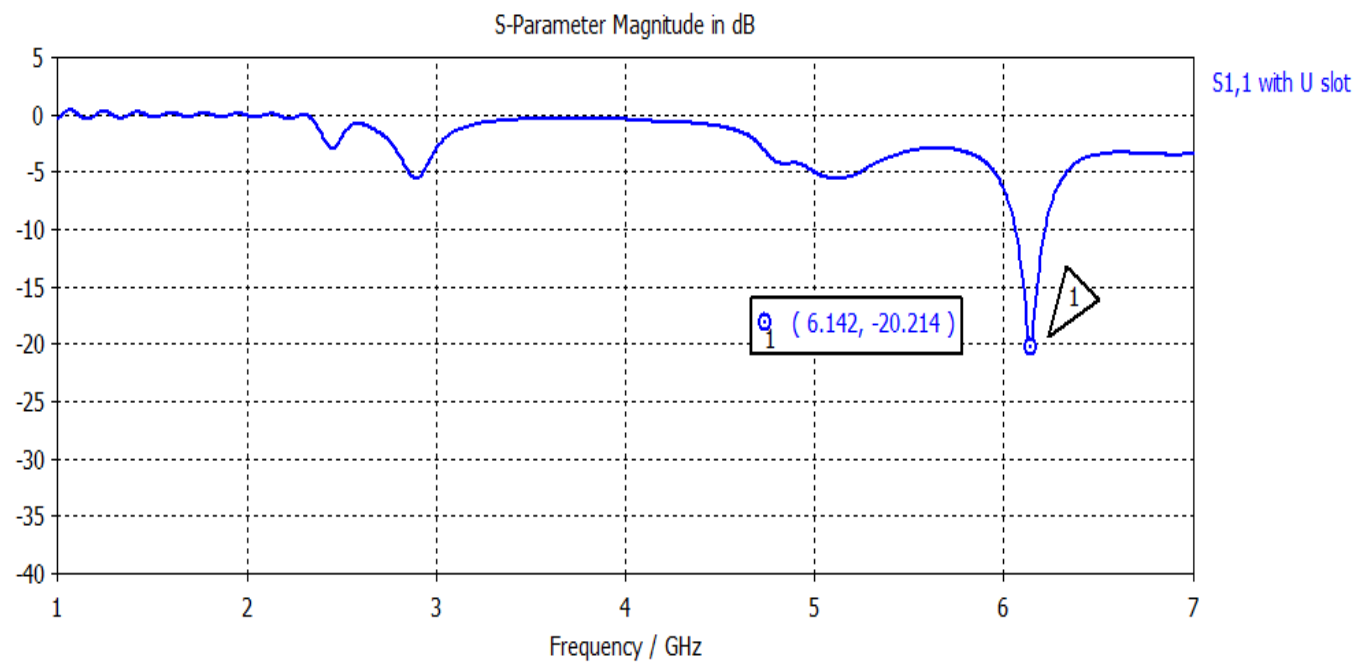

(a) 


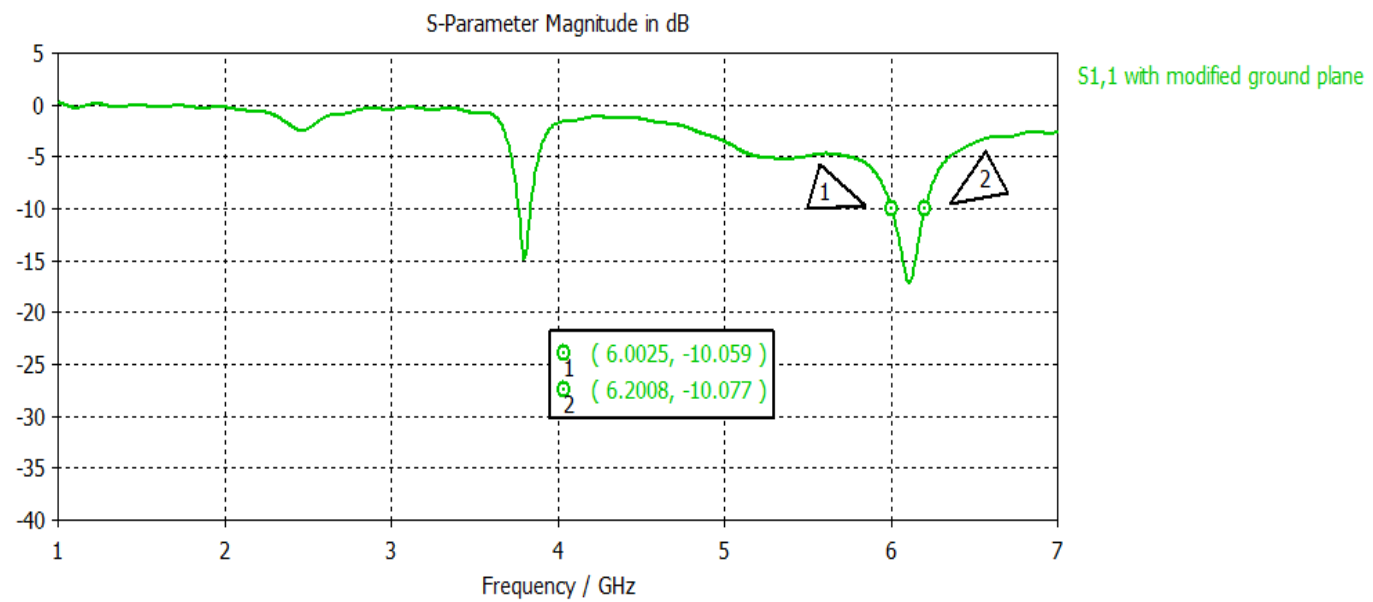

(b)

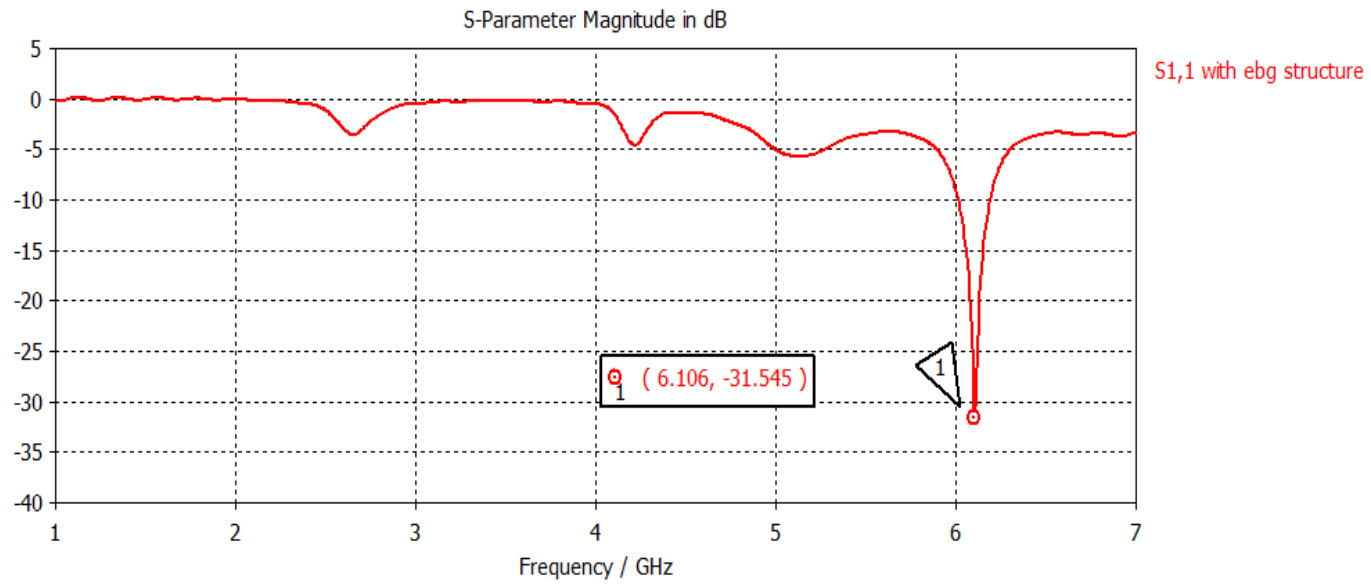

(c)

Fig.2. Simulated Reflection Coefficient versus Frequency Plots of U-Slot MPA: (a) Patch with U-slot only, (b) Patch with U-slot and DGS, (c) Patch with U-slot, DGS and EBG

The return loss curve of U-slot microstrip patch antenna shown in Fig. 2(a) demonstrates that return loss is $20.2 \mathrm{~dB}$ and bandwidth is $155 \mathrm{MHz}$ for the resonating frequency of $6.1 \mathrm{GHz}$ [16]. By modifying the ground plane using circular slots in it, the bandwidth was improved to $202 \mathrm{MHz}$ but the return loss reduced to -17.14 $\mathrm{dB}$ as shown in Fig. 2(b).

To compensate for the decrease in return loss, mushroom like EBG structures were deployed on the substrate surface around the patch. As a result, the return loss in the $6.1 \mathrm{GHz}$ resonating band showed remarkable improvement to $-31.5 \mathrm{~dB}$ and back lobes suppression shown in Fig. 2(c).

\subsection{Current Distribution Results}

The return loss can only depict the behaviour of the antenna as a lumped load at the end of the feeding line. The analysis of field/current distributions beneath and over the patch can only reveal the detailed electromagnetic behaviour of the antenna. 


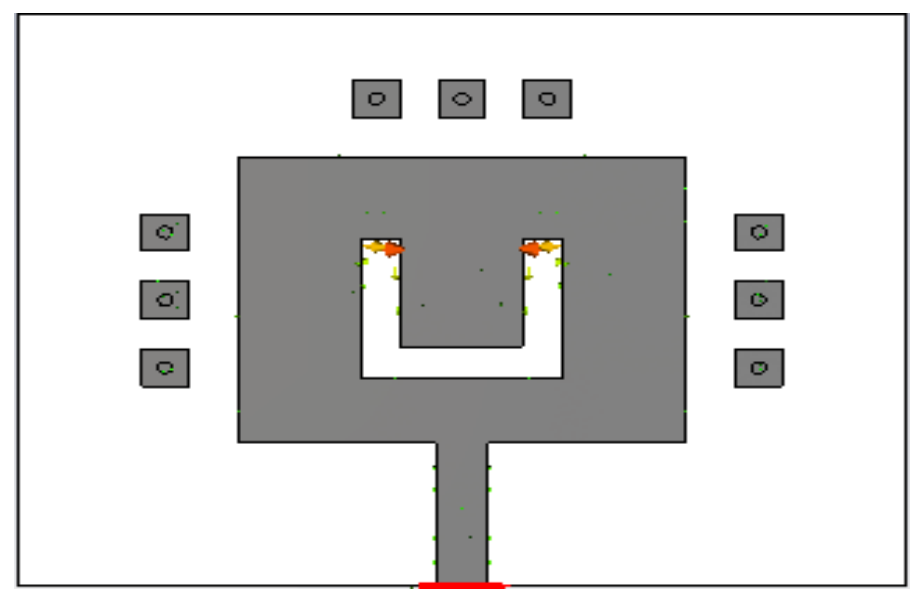

(a)

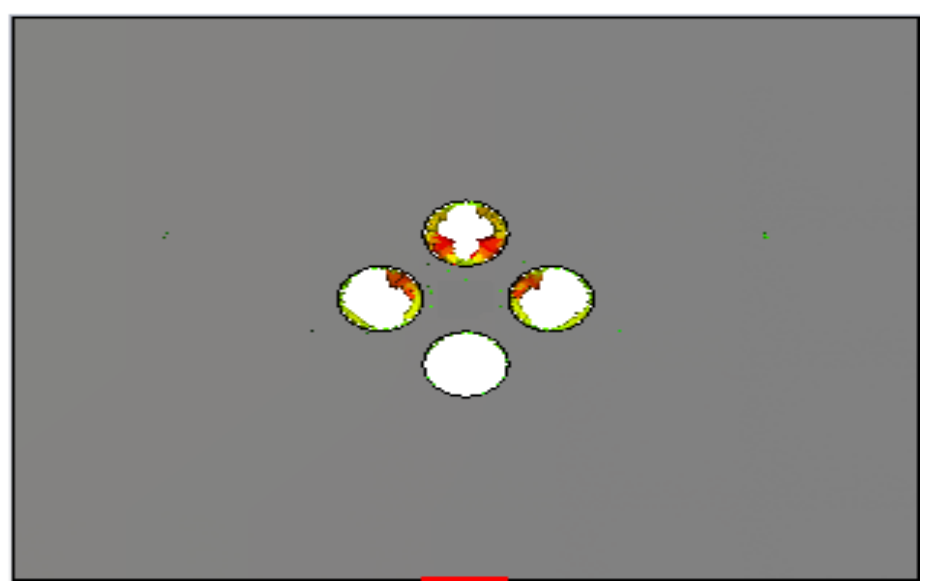

(b)

Fig.3. Distributions of the Surface Current of the Proposed Antenna at 6.1 GHz: (a) Front view of the Antenna, (b) Back view of the Antenna

The typical current distributions of the antenna at the resonating frequency $6.1 \mathrm{GHz}$ is depicted in Fig. 3(a) and 3(b). From above Figures, it can be observed that the upper ends of the U-slot patch situated at the centre of the substrate and circular shaped defected ground structure constructed in the ground plane are strongly responsible for enhancing the bandwidth for the band resonating at $6.1 \mathrm{GHz}$. The above Figure also illustrates that the current distribution in electromagnetic band gap structures is responsible for the improvement in the return loss and suppression of the back lobes.

\subsection{Directivity}

Another fundamental parameter of antenna that is directivity is the measure how directional the radiation pattern is. It is important to understand the requirement for high directivity antenna to maximize the power transfer in a particular direction and reduce signal from unwanted directions. Fig. 4 depicts the simulated three dimensional directivity pattern of the proposed antenna that comes out to be $7.09 \mathrm{dBi}$ at $6.1 \mathrm{GHz}$. 


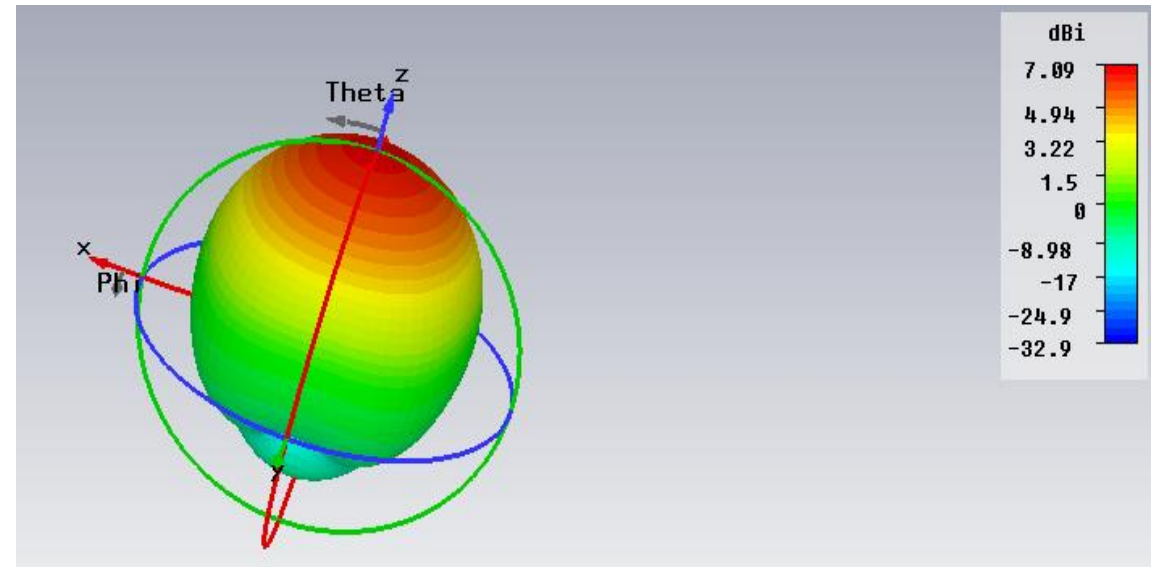

Fig.4. Simulated 3D Directivity Pattern of Proposed Antenna at $6.1 \mathrm{GHz}$.

\subsection{Gain}

Antenna gain describes power transmitted in the direction of peak radiation to that of an isotropic source.

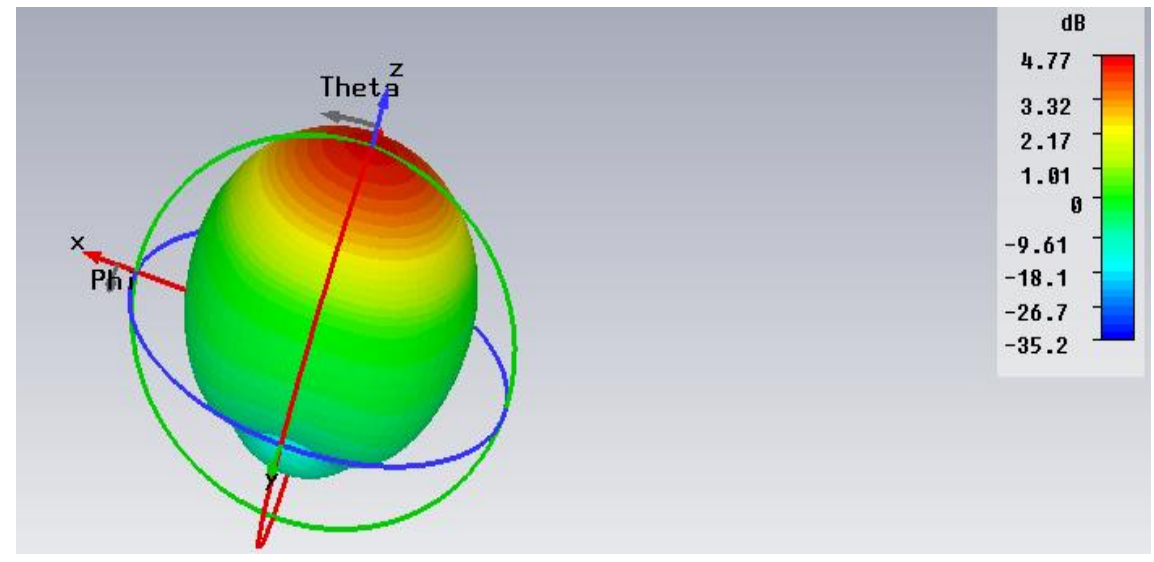

Fig.5. Simulated 3D Plot of Gain of Antenna at 6.1 GHz.

An antenna with a gain of $3 \mathrm{~dB}$ depicts that the power received far from the antenna is $3 \mathrm{~dB}$ higher almost twice than that would be received from a lossless isotropic antenna with same input power. Fig. 5 depicts the simulated three dimensional plot of the gain of antenna is $4.77 \mathrm{~dB}$ at $6.1 \mathrm{GHz}$.

Hence EBG and DGS have played a significant role in enhancing the return loss, gain, directivity and bandwidth of the proposed antenna.

\section{Conclusions}

A compact microstrip U-slot patch antenna using DGS involving circular slots was proposed in this paper. The use of mushroom like EBG structure to achieve the enhanced performance of antenna resonating at 6.1 $\mathrm{GHz}$ is also discussed. Firstly, the microstrip patch antenna with U-Slot only demonstrates the return loss of - 
$20.2 \mathrm{~dB}$ and bandwidth $155 \mathrm{MHz}$ Secondly, by modifying the ground plane using circular slots in it, the bandwidth was improved to $202 \mathrm{MHz}$ but the return loss reduced to $-17.14 \mathrm{~dB}$. Finally, to compensate for the decrease in return loss, mushroom-like EBG structures were composed around the patch resulting in refinement of return loss to $-31.5 \mathrm{~dB}$ and remarkable suppression in back lobes. The above designed antenna is appropriate for Radio Frequency portable devices operating at 6-7 GHz.

\section{Conflict of Interests}

The authors declare that there is no conflict of interests regarding the publication of this paper.

\section{Acknowledgement}

The authors greatly acknowledge the help provided by Electronics and Communication Engineering Department, T.U., Patiala by providing the necessary software for designing antenna and various infrastructural facilities for the successful completion of this paper.

\section{References}

[1] Y. Yao, X. Wang, and Z. Feng, "A novel dual- band compact electromagnetic bandgap (EBG) structure and its application in multi-antennas," IEEE Antennas Propagation Society. International Symposium, pp. 1943-1946, 2006.

[2] I. Chang and B. Lee, "Design of defected ground structures for harmonic control of active microstrip antenna," IEEE Antennas Propagation Society International Symposium, vol. 2, pp. 852-855, 2002.

[3] C. C. Chiau, X. Chen, and C. Parini, "Multi period EBG structure for wide stop band circuit," IEEE Microwave Antennas Propagation, vol. 150, pp. 489-492, Dec. 2003.

[4] M. Bozzetti et al., "Tapered photonic band gap microstrip low pass filters: Design and realization," in Proceeding IEEE Microwave Antennas Propagation, vol. 150, pp. 459-462, Dec. 2003.

[5] Y. J. Sung, M. Kim, and Y.-S. Kim, "Harmonic reduction with defected ground structure of a microstrip patch antenna," IEEE Antennas Wireless Propagation Letters, vol. 2, pp. 111-113, 2003.

[6] J.-S. Yoon et al., "A new DGS resonator and its application to band pass filter design," Proceeding IEEE Microwave Theory Techniques-Society Dig., pp. 1605-1608, 2004.

[7] J.-S. Lim, C.-S. Kim, Y.-T. Lee, D. Ahn, and S. Nam, "A spiral shaped defected ground structure for coplanar waveguide," IEEE Microwave. Component Letters, vol. 12, no. 9, pp. 330-332, 2002.

[8] E. K. I. Hamad, A. M. E. Safwat, and A. S. Omar, "Controlled capacitance and inductance behaviour of L-shaped defected ground structure for coplanar waveguide," Proceeding IEEE Microwave Antennas Propagation, vol. 152, pp. 299-304, 2005.

[9] Jaswinder Kaur, "Development of Dual Band Microstrip Patch Antenna for WLAN /MIMO/ WiMAX/AMSAT/WAVE Applications", Microwave and Optical Technology Letters, vol. 56, no. 8, pp. 1965-1970, 2014.

[10] Jaswinder Kaur, Rajesh Khanna \& M. V. Kartikeyan, "Optimization and Development of O-Shaped Triple band Microstrip Patch Antenna for Wireless Communication Applications", IETE Journal of Research, vol. 60, no. 2, pp. 95-105, 2014.

[11] Y.-Q. Fu, N.-C. Yuan, and G.-H. Zhang, "A novel fractal microstrip PBG structure," Microwave Optical Technology Letters, vol. 32, pp. 136-138, 2002.

[12] Nasimuddin, Zhi Ning Chen, and Xianming Qing "Dual-Band Circularly Polarized -Shaped Slotted Patch 
Antenna with a Small Frequency - Ratio" IEEE Transactions on Antennas and Propagation, vol. 58, no. 6, 2010.

[13] Jaswinder Kaur, Rajesh Khanna and M.V. Kartikeyan, "Novel Dual Band Microstrip Monopole Antenna With Defected Ground Structure for WLAN/IMT/Bluetooth/WiMAX Applications", International Journal of Microwave and Wireless Technologies, vol. 6, no. 1, pp. 93-100, 2014.

[14] Nayeri, P.Lee, K.-F.Elsherbeni, A.Z. and Fan Yang "Dual-Band Circularly Polarized Antennas Using Stacked Patches with Asymmetric U-Slots" IEEE Antennas and Wireless Propagation Letters, vol. 10, 2011.

[15] Ravindra Kumar Yadav, Jugul Kishor, R. L. Yadava," Effects of Superstrate on electromagnetically and Gap Coupled Patch Antennas", International Journal of Wireless and Microwave Technologies (IJWMT), vol.4, no.3, pp.26-35, 2014.

[16] Shagun Maheshwari, Priyanka Jain, Archana Agarwal ,"CPW-fed Wideband Antenna with U-shaped Ground Plane", International Journal of Wireless and Microwave Technologies (IJWMT), vol.4, no.5, pp.25-31, 2014.

\section{Authors' Profiles}

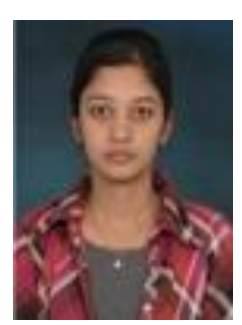

Nitika Mittal received her B.Tech degree in Electronics and Communication Engineering in 2013 from Chitkara University, Rajpura, Punjab, India and M.E degree in 2015 from Thapar University, Patiala, Punjab, India. Her research interest includes analysis and design of various types of antennas like microstrip patch antennas, dielectric resonator antennas etc.

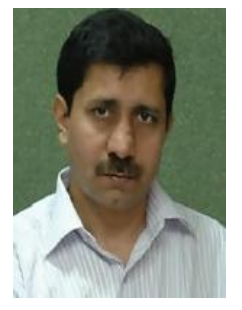

Dr. Rajesh Khanna received his B.Sc. (Eng.) Degree in Electronics and Communication in 1988 from the Regional Engineering College, Kurukshetra, Haryana, India and M.E. degree in 1998 from Indian Institute of Sciences, Bangalore, India. Presently he is working as a Professor, Department of Electronics and Communication, Thapar University, Patiala, Punjab, India. He has published 80 papers in national and international journals/conferences. He has research projects worth Rs 1.5 crore to his credit. His research interest includes the analysis and design of antennas, wireless communication, MIMO, and fractional Fourier transformbased wireless systems.

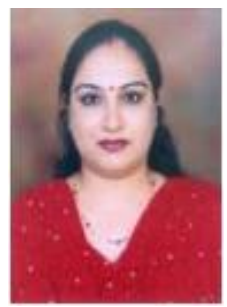

Dr. Jaswinder Kaur received her Ph.D. degree from "Department of Electronics and Communication Engineering", Thapar University, Patiala, Punjab, India in 2014. Her M.Tech. and B.Tech. degrees are from Punjab Technical University, Jalandhar, in 2009 and 2005 respectively. She has been in the profession of teaching since July 2005. She has 24 publications in national and international peer reviewed journals/conferences, to her credit. Her research interests include the Analysis and Design of Microstrip Antennas and Wireless Communication Systems. 